Review

\title{
Western Individualism and the Psychological Wellbeing of Young People: A Systematic Review of Their Associations
}

\author{
Ashley Humphrey ${ }^{1, * \mathbb{D}}$ and Ana-Maria Bliuc ${ }^{2}$ \\ 1 School of Science, Psychology and Sport, Federation University, Mt Helen, VIC 3350, Australia \\ 2 Department of Psychology, University of Dundee, Dundee DD1 4HN, UK; abliuc001@dundee.ac.uk \\ * Correspondence: a.humphrey@federation.edu.au
}

Citation: Humphrey, A.; Bliuc, A.-M. Western Individualism and the Psychological Wellbeing of Young People: A Systematic Review of Their Associations. Youth 2022, 2, 1-11. https: / / doi.org/10.3390/ youth 2010001

Academic Editor: Todd Michael Franke

Received: 20 October 2021

Accepted: 16 December 2021

Published: 22 December 2021

Publisher's Note: MDPI stays neutral with regard to jurisdictional claims in published maps and institutional affiliations.

Copyright: (c) 2021 by the authors. Licensee MDPI, Basel, Switzerland. This article is an open access article distributed under the terms and conditions of the Creative Commons Attribution (CC BY) license (https:// creativecommons.org/licenses/by/ $4.0 /)$.

\begin{abstract}
An increasing body of research suggests that young people living in Western societies are becoming increasingly individualistic in the way they orientate themselves socially, with further findings suggestive that such orientations may be associated with reduced wellbeing outcomes. Through a systematic review of past research, this paper examines the findings on individualism and the wellbeing of young people living within Western contexts. Findings from our review indicate that whilst individualistic cultures may be associated with higher wellbeing outcomes when compared with collectivistic cultures, such associations tend to disappear when explored the personal level. Additionally, we find that distinguishing how individualism is measured provides important insight into specific traits associated with individualism that can lead to poorer wellbeing outcomes. Based on the studies reviewed, we propose that whilst the freedom and autonomy embedded within individualistic social orientations can have positive associations, there is an emerging understanding of some of the darker traits that can be associated with these values. These synthesized findings increase our understanding of the connection between individualism, its associated behaviours, and the mental health of young people.
\end{abstract}

Keywords: social values; individualism; collectivism; wellbeing; youth

\section{Introduction}

Despite the significant economic, health and educational advantages that exist for young people living in high income Westernised countries today when compared to previous generations, there is an increasing body of evidence suggesting that the psychological wellbeing of young people in these environments is in decline [1-3]. A selection of generational data on mental health for instance, points towards an increase in the amount of psychological health issues experienced by young people in Western contexts over the preceding decades [3-5]. Though such findings are not without limitation, with the influence of population growth and changes in self-report metrics relevant contributors, researchers argue that they deserve greater attention [3-6].

In response to this data indicating a potential decline in young people's mental health, some research has pointed towards a number of cultural shifts in Western environments that may be impacting upon these statistics [5,6]. Specifically, the increasing 'individualisation' of Western societies is thought to be one potential contributor to this challenging cultural climate facing young people living in such settings [6-8]. Individualism is defined by Triandis and Gelfand [9] as an orientation towards independence and self-reliance, pursuing personal goals, maintaining relationships when the costs do not outweigh the benefits, and having the freedom to express oneself. This is in contrast with the dynamics surrounding collectivism - whereby societies are oriented around shared groups, identities and goals. Oyserman and colleagues [10], provide a further distinction to these definitions, stating that attaining personal goals, happiness and personal control are assumed central to wellbeing within individualism, whereas carrying out obligations and duties are assumed central to wellbeing within collectivism. 
Individualistic values are said to be largely unique to Western countries, whereby greater economic, political and social liberties allow for high levels of individual autonomy, and social behaviours and values are influenced accordingly [11,12]. Young people living in high income, Westernised societies are shown to be particularly likely to adopt individualistic social orientations $[13,14]$ with this trend shown to have increased over the past few decades [8]. In reviewing generational data collected from American College students from 1966 to 2009, Twenge and colleagues [8] for instance show that the millennial generation (those born between 1982 and 2003) are less caring towards others, and more oriented towards individualistic values and behaviours when compared with previous generations. The authors point to cultural influences specific to American society (and Western society more generally) as being responsible for this shift in social orientations, citing increasing economies and the resultant freedoms they allow for certain demographics of young people to make important life decisions, as important contributors.

The cultural dynamisms of individualism and collectivism have served as a key social distinction when exploring wellbeing and life satisfaction outcomes across differing cultures. Cross-cultural research has shown that the economic and libertarian advantages that accompany individualistic cultures leads to positive associations between individualistic countries and subjective wellbeing when compared with collectivist cultures [15,16]. Further research has shown individualistic societies to associate with enhanced human rights, self-determinism and economic opportunities [10,17,18]. Ahuvia [19] theorises that it is these associations that have allowed individualism to liberate the individual from the bounds of pure collectivism and class hierarchy and enhance one's social liberties, which in turn equates to increased quality of life outcomes.

Despite these positive associations between individualistic cultures and wellbeing when contrasted with collectivistic cultures, research on individualism and wellbeing conducted at the personal level of analyses provides a contrasting set of findings. Studies that have focused on how orientations towards individualism relate to wellbeing at the personal level (rather than across cultures) show individualistic values to be associated with higher levels of isolation [20], suicidal tendencies [21,22] and poorer psychological health [23]. As a means of gaining clarity on these seemingly conflicting findings between individualism and wellbeing that exist between the cultural versus personal level of analyses, a number of studies have broken the concepts down into differing sub-traits [23-25]. In particular, studies have largely drawn on Triandis and Gelfand's [9] 'vertical' and 'horizontal' dimensions of individualism and collectivism. These distinctions define firstly horizontal individualism as emphasising uniqueness and autonomy, yet rather than aspiring to stand out, people instead focus on becoming independent. Vertical individualism similarly defines a focus on independence, but also embodies traits of extreme self-sufficiency and competitiveness as well. Horizontal collectivism then emphasises common goals and cooperativeness between an individual and their community, while vertical collectivism is defined as a complete submission and dutifulness to the authorities of one's community. Germani et al. [24] note that studies applying this horizontal and vertical distinction to examining individualism and collectivism warrant greater attention, as they provide greater comprehension around the previously acknowledged association between individualism and positive wellbeing outcomes. Indeed, whilst individualistic environments allow for increased personal freedoms to pursue one's own personal goals [15,18], recent findings drawing on these sub-definitions of individualism indicate that socially orienting oneself in a highly individualistic way may also comprise a range of subtle detriments. This is specific to the traits of self-sufficiency and competitiveness individualistic values can lead to, that can in turn be harmful to one's psychological wellbeing [23-25]. In line with this evolving body of research, as well as the findings indicating that young people are shown to be more individualistic than previous generations, we aim throughout this review to give an updated account on the literature of how the cultural concept of individualism relates to the psychological wellbeing of young people living in Westernised environments. By reviewing studies according to their level of analysis (i.e., cross-cultural or individual), 
our review aims to bring clarity to the relationship individualism has on the wellbeing of young people living within noted individualistic environments.

This review will employ a focus on empirical literature, published in English, that explores the association between individualistic values and wellbeing amongst youth living in Westernised environments. We choose to focus our review on Western environments, as research suggests that the relationship between individualism and wellbeing operationalizes very differently in Eastern versus Western cultures [26]. This is said to be due to the differences in socioeconomic, political and social circumstance that can exist amidst these differing environments [26]. Further, according to Hofstede's [12] cross-cultural indicators, high-income Western nations are shown to score particularly high on individualism when compared with Eastern countries that tend to be more collectivistic, making Western contexts a good case study to focus our investigation on.

It is important to note here that we acknowledge that not all young people are equally affected by their attachment to individualistic values-with different ethnicities, socioeconomic circumstances important moderators-nor are all influences equally consistent across all Western populations. Indeed, as Eckersley and Dear [21] address in their analyses of cultural influences on youth suicide-cultures are not universal, with a variety of subcultures also marked by potentially very different values and beliefs. This article wishes to acknowledge these points, yet seeks to addresses these issues from a broader cultural perspective, proposing that greater emphasis should be placed on cultural concepts such as individualism in relation to how they influence the wellbeing of young people. We categories young people here within the emerging adulthood bracket (18-29 years of age), as that is the demographic that the vast majority of youth focused research exploring the effects of individualism on wellbeing focuses on. The concept of wellbeing is used here as an umbrella term capturing one's satisfaction with their physical, psychological and spiritual health, their relationships, their security, their achievements and their attachment to community [27]. It also includes a psychological element operationalised as the absence of anxiety and depression. As such this research will conceptualise psychological wellbeing as a dynamic notion that includes subjective, social and psychological dimensions as well as health-related behaviors [27], and will therefore utilize studies that have allowed for such a broad definition of wellbeing.

\section{Methods}

The first step of the review process was a comprehensive search of past research conducted between 1990 and 2021 undertaken by the first author. The key words used were 'individualism', 'collectivism' and 'wellbeing', and articles were sorted by specifying that these terms were present within the articles title, keyword or abstract. Our searches were conducted in the following databases: Pro Quest (105 results), Scopus (42 results), Web of Science ( 36 results) and PubMed (43 results). We compiled the results of each database used into a single document, and then deleted all duplicates. Further searchers were made using the reference list of each of the identified articles to find other potential studies relevant to our search, as was Google Scholar and a University Library Database.

The inclusion criteria that we applied to our search were: (a) empirical research that reported quantitative data (purely theoretical papers and qualitative studies were excluded); (b) the key concept of individualism was examined and measured via a scale specifically designed to measure individualistic orientations; (c) studies included wellbeing as one of the variables of interest; (d) participant samples included a focus on young people (aged 18-29) living within Westernised countries; and (e) be published in (peer-reviewed) journal articles from 1990 to 2021 (we chose to focus on this time frame as this encapsulates literature published within the life span of the current generation of emerging adults). We then selected those studies that met our criteria. Papers were excluded if they did not include a youth-based participant sample from within a Westernized country.

In total fourteen studies that met our criteria were selected to be included in the review. These studies were reviewed and information on their theoretical approach, methodology 
and key findings was extracted - to provide an overview of how the concepts of individualism and, where relevant collectivism, were researched, the potential association these concepts had with each other, as well as their effects on the wellbeing of young people-or general population groups were applicable. The flow of our process of selection of articles is represented following the recommendations of PRISMA [28]—please refer to Figure 1 for more details.

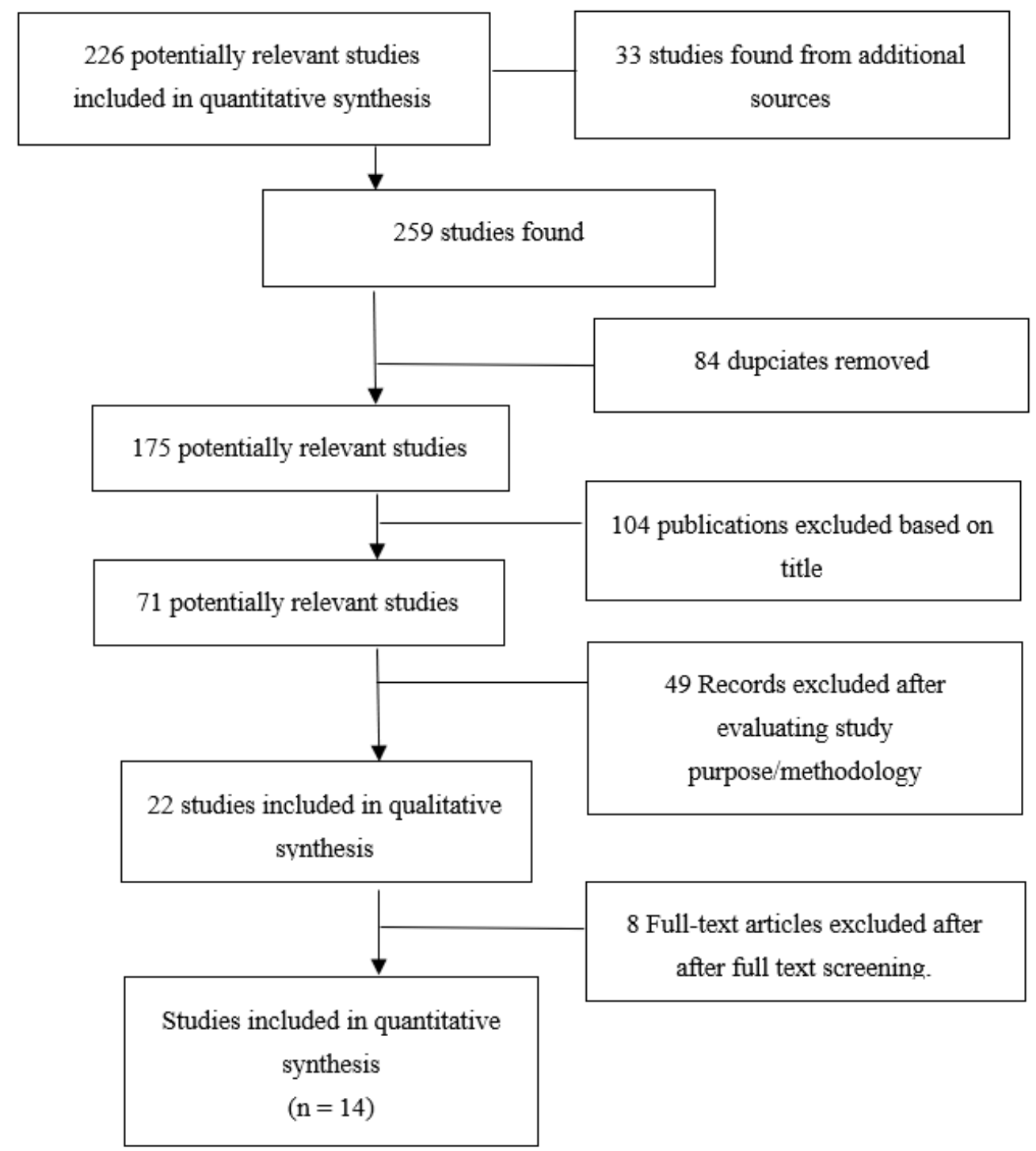

Figure 1. Study selection flow chart.

\section{Data Extraction and Synthesis}

The final 14 papers were reviewed by the authors using a standardised data extraction tool-in the form of a table specifically designed by the authors for this review. Here the authors looked at the study sample population, study type, study setting, level of anaylisis, and a description of the research method, results and conclusions. The authors then extracted key findings from each paper in relation to our reviews focus: the relationship between individualism and collectivism and young Western people's wellbeing. This was done in line with the conceptual framework underpinning the analysis. 


\section{Findings}

\subsection{Characteristics of the Studies Reviewed} Instruments and Methods Used

The majority of research reviewed for this paper was conducted focusing on individualism and wellbeing at an individual level (i.e., exploring how individualism relates to wellbeing in a specified cultural context) $(n=9)$, with a few additional studies based on cross-cultural analyses $(n=5)$. Where cross-cultural samples were included, we chose to focus on the results specific to the Western nations within the data. Scales used to measure individualism and collectivism were Triandis and Gelfand [9] measurement of horizontal and vertical individualism and collectivism $(n=6)$ as well as Triandis [29] earlier measurement of horizontal and vertical individualism and collectivism $(n=1)$; and Triandis [30] Individualism and Collectivism Scale $(n=1)$. Other scales used were Singelis [31] measurement of independent and interdependent self-construals $(n=2)$, Hui's [32] Measurement of individualism-collectivism $(n=1)$; Crocker et al. [33] Contingencies of self-worth measure $(n=1)$; a combination of Hofstede's Individualism Index Value as described by Cheng et al. [34] as well as Suh's individualism-collectivism rating [35], and a selection of questions from the World Values Survey [36] $(n=1)$. These measures have been widely validated, and possess good psychometric properties [10]. All scales possess questions that clearly distinguish between items that relate to individualism, explicated in the above scales by items that focus on valuing personal independence and autonomy, with all measures including at least one item focused on 'valuing personal independence'. While the collectivism items all included a focus on shared group goals and preferences, and at least one item focused on sense of duty to group' as well as 'relatedness to others'. Within our sample, more than half of studies drew on Triandis and Gelfand's [9] or Triandis [29] measurement of horizontal and vertical individualism and collectivism, with this scale allowing for the sub-factors of vertical and horizontal individualism and collectivism to be investigated in how they relate to wellbeing.

Wellbeing was measured predominantly by the Satisfaction with Life Scale (SWLS) [37] $(n=8)$; the Depression Anxiety and Stress Scales (DASS21) [38] $(n=2)$; while the Center of Epidemiology Scale-Depression factor (CES-D) [39] $(n=1)$; The Beck Depression Inventory-II (BDI-II) [40] $(n=1)$; Attitudes Towards Suicide Scale (EATSS) [41] $(n=1)$ and WHO mental health data $(n=1)$ were also used. Generally speaking, studies focused on one wellbeing outcome measure, however when multiple measures of wellbeing were drawn on, we focused on composite outcomes as defined within the relevant studies results sections. All this information is categorized in Table 1.

Table 1. Key literature on individualism and wellbeing.

\begin{tabular}{|c|c|c|c|c|c|}
\hline $\begin{array}{l}\text { Lead } \\
\text { Author } \\
\text { (Year) }\end{array}$ & $\begin{array}{l}\text { Sample } \\
\text { Type }\end{array}$ & $\begin{array}{l}\text { Ind/Coll } \\
\text { Measure }\end{array}$ & $\begin{array}{l}\text { Outcome } \\
\text { Measure(s) }\end{array}$ & $\begin{array}{l}\text { Level of } \\
\text { Analysis }\end{array}$ & Main Findings \\
\hline Nezlek 2021 & $\begin{array}{c}\text { US: } \\
\text { Emerging } \\
\text { adults }\end{array}$ & $\begin{array}{c}\text { Triandis } \\
1998\end{array}$ & $\begin{array}{c}\text { CES-D, Ryff } \\
\text { WB (1989) }\end{array}$ & Individual & $\begin{array}{l}\text { Found that individualism was negatively related to } \\
\text { wellbeing, with this relationship varied between } \\
\text { horizontal and vertical dimensions of } \\
\text { individualism. Both horizontal and vertical } \\
\text { collectivism were laregly positively related to all } \\
\text { measures of wellbeing. }\end{array}$ \\
\hline $\begin{array}{l}\text { Germani } \\
2021\end{array}$ & $\begin{array}{c}\text { US, Italy, } \\
\text { Russia and } \\
\text { China: } \\
\text { Emerging } \\
\text { adults }\end{array}$ & $\begin{array}{c}\text { Triandis } \\
1998\end{array}$ & SWLS & $\begin{array}{c}\text { Individual \& } \\
\text { National }\end{array}$ & $\begin{array}{l}\text { When compared across four cultures, life } \\
\text { satisfaction was unrelated to horizontal or vertical } \\
\text { individualism, but was positively associated with } \\
\text { horizontal and vertical collectivism. Similarly at the } \\
\text { individual level both dimensions of collectivism } \\
\text { related positively to life satisfaction, while } \\
\text { individualism was insignificant across all } \\
\text { nations investigated. }\end{array}$ \\
\hline
\end{tabular}


Table 1. Cont.

\begin{tabular}{|c|c|c|c|c|c|}
\hline $\begin{array}{l}\text { Lead } \\
\text { Author } \\
\text { (Year) }\end{array}$ & $\begin{array}{l}\text { Sample } \\
\text { Type }\end{array}$ & $\begin{array}{l}\text { Ind/Coll } \\
\text { Measure }\end{array}$ & $\begin{array}{c}\text { Outcome } \\
\text { Measure(s) }\end{array}$ & $\begin{array}{l}\text { Level of } \\
\text { Analysis }\end{array}$ & Main Findings \\
\hline $\begin{array}{c}\text { Humphrey } \\
2020\end{array}$ & $\begin{array}{l}\text { Australia: } \\
\text { Emerging } \\
\text { adults }\end{array}$ & $\begin{array}{c}\text { Triandis } \\
1998\end{array}$ & DASS21 & Individual & $\begin{array}{c}\text { Orientations towards vertical individualism } \\
\text { predicted lower levels of psychological wellbeing, } \\
\text { while orientations towards horizontal collectivism } \\
\text { predicted higher psychological wellbeing. } \\
\text { Horirontal individualism and vertical colelctivism } \\
\text { were non-signfigant. }\end{array}$ \\
\hline Krys 2019 & $\begin{array}{l}\text { Cross } \\
\text { Cultural: } \\
\text { Emerging } \\
\text { adults }\end{array}$ & Singelis 1994 & SWLS & $\begin{array}{c}\text { Individual \& } \\
\text { National }\end{array}$ & $\begin{array}{l}\text { Based on data collected from } 12 \text { countries, a } \\
\text { positive association shown between life satisfaction } \\
\text { and individualism was found when compared } \\
\text { across cultures. These associations between } \\
\text { individualism and wellbeing were reduced } \\
\text { however when measured agianst modified social } \\
\text { based items of the SWLS. }\end{array}$ \\
\hline Lin 2017 & $\begin{array}{l}\text { Australia/Singa1 } \\
\text { Emerging } \\
\text { Adults }\end{array}$ & $\begin{array}{l}\text { apore: } \\
\text { Triandis } \\
1998\end{array}$ & DASS21 & National & $\begin{array}{l}\text { Individualism and collectivism were significantly } \\
\text { associated with attachment avoidance but } \\
\text { not anxiety. }\end{array}$ \\
\hline $\begin{array}{c}\text { Zalewska } \\
2016\end{array}$ & $\begin{array}{l}\text { Polish: } \\
\text { Emerging } \\
\text { Adults }\end{array}$ & $\begin{array}{c}\text { Triandis } \\
1998\end{array}$ & SWLS & Individual & $\begin{array}{l}\text { Found a positive relationships between the } \\
\text { horizontal and vertical dimensions of collectivism, } \\
\text { and horizontal dimension of individualism and } \\
\text { wellbeing, whereas vertical individualism related } \\
\text { negatively to wellbeing. }\end{array}$ \\
\hline Cheng 2016 & $\begin{array}{l}\text { Cross- } \\
\text { Cultrual: } \\
\text { Emerging } \\
\text { Adults }\end{array}$ & $\begin{array}{l}\text { Hofstede } \\
\text { 2014/Suh } \\
\quad 1998\end{array}$ & SWLS & National & $\begin{array}{c}\text { Individualism was not significantly linked with any } \\
\text { components of subjective wellbeing at the } \\
\text { national level. }\end{array}$ \\
\hline $\begin{array}{l}\text { Ogihara } \\
2014\end{array}$ & $\begin{array}{l}\text { US/Japan: } \\
\text { Emerging } \\
\text { Adults }\end{array}$ & $\begin{array}{l}\text { Crocker, } \\
2003\end{array}$ & SWLS & National & $\begin{array}{l}\text { Individualism not associated with any negative } \\
\text { shift in subjective wellbeing in US populations, } \\
\text { however it is shown to associate negatively with } \\
\text { wellbeing in a Japanese context. }\end{array}$ \\
\hline Eskin 2013 & $\begin{array}{l}\text { Turkey: } \\
\text { Emerging } \\
\text { Adults }\end{array}$ & Singelis 1994 & Eskin EATSS & Individual & $\begin{array}{l}\text { Individualistic tendencies associated with more } \\
\text { permissive attitudes toward suicide when } \\
\text { compared with collectivistic tendencies. }\end{array}$ \\
\hline Scott 2004 & $\begin{array}{l}\text { Australia: } \\
\text { Emerging } \\
\text { adults }\end{array}$ & $\begin{array}{c}\text { Triandis } \\
1998\end{array}$ & BDI 1996 & Individual & $\begin{array}{l}\text { Individualism associated with poorer social } \\
\text { support, less satisfying social networks and } \\
\text { diminished psychological wellbeing indicators. }\end{array}$ \\
\hline Yetim 2003 & $\begin{array}{l}\text { Turkey: } \\
\text { Emerging } \\
\text { adults }\end{array}$ & Hui 1988 & SWLS 1985 & Individual & $\begin{array}{c}\text { Findings specific to the University student cohort } \\
\text { within this participant sample revealed that } \\
\text { individualism predicted high life satisfaction and } \\
\text { collectivism predicted low life satisfaction in } \\
\text { Turkish young people. }\end{array}$ \\
\hline $\begin{array}{l}\text { Eckersley } \\
2002\end{array}$ & $\begin{array}{l}\text { Cross- } \\
\text { cultural: } \\
\text { adolec- } \\
\text { sents/Emerging } \\
\text { adults }\end{array}$ & $\begin{array}{l}\text { Veenhoven } \\
1999\end{array}$ & $\begin{array}{c}\text { WHO } \\
\text { Suicide data }\end{array}$ & National & $\begin{array}{l}\text { Individualism associated with higher levels of } \\
\text { wellbeing when looked at across cultures, however } \\
\text { individualistic cultures also associated with a } \\
\text { higher suicide rates for young people when } \\
\text { compared to collectivistic ones. }\end{array}$ \\
\hline Oishi 2000 & $\begin{array}{l}\text { Cross- } \\
\text { cultural: } \\
\text { Emerging } \\
\text { adults } \\
\text { (College } \\
\text { Students) }\end{array}$ & $\begin{array}{c}\text { Traindis } \\
1995\end{array}$ & SWLS & National & $\begin{array}{l}\text { Horizontal individualism positively associated } \\
\text { with wellbeing in the pre-identified individualistic } \\
\text { nations (but not in the collectivistic nations), while } \\
\text { horizontal collectivism was positively associated } \\
\text { with wellbeing in most collectivistic nations. } \\
\text { Vertical individualism related negatively to } \\
\text { wellbeing in most countries investigated. }\end{array}$ \\
\hline $\begin{array}{c}\text { Bettencourt } \\
1997\end{array}$ & $\begin{array}{l}\text { US: } \\
\text { Emerging } \\
\text { Adults }\end{array}$ & $\begin{array}{c}\text { Traindis } \\
1988\end{array}$ & SWLS & Individual & $\begin{array}{c}\text { Across } 2 \text { studies individualism was negatively } \\
\text { correlated with wellbeing, while collectivism } \\
\text { related positively with wellbeing. }\end{array}$ \\
\hline
\end{tabular}




\section{Results}

\section{Findings: Individualism and Wellbeing}

Finding across the 14 studies reviewed largely showed individualism to be associated with a reduced satisfaction with life, along with an increased likelihood of depressive symptomology and suicide ideation in young people. This was not exclusively the case, with the nine cross-cultural studies included in this review revealing mixed results. Focusing on both Japanese and US emerging adults, Ogihara [42] found that individualistic orientations did not impact upon a composite measure of subjective wellbeing (SWB), whilst collectivistic orientations negatively impacted wellbeing in the US sample (but not the Japanese sample, whereby individualism negatively affected SWB). Analysing data collected from college students in twelve different countries, Krys et al. [43] found that individualism was significantly associated with higher levels of satisfaction with life when looked at across nations. However, when analysed against a modified version of the SWLS that measured one's satisfaction with their social relationships, the association between individualism and wellbeing reduced. In an earlier study of college students from 33 nations, individualism had no effect on wellbeing [34]. In a study of emerging adults from China, Italy, Russia and the US, Germani et al. [24] similarly found that individualistic values were positively related to satisfaction with life when contrasted across nations. At the individual level, however, this effect between either dimension of individualism was non-significant in all countries, and alternately there was a positive association between both vertical and horizontal collectivism and life satisfaction.

Cross-cultural findings on individualism and wellbeing are noted as being somewhat inconclusive, due to a range of other variables present within the data such as a nations level of wealth, that can conflate the clarity of this relationship [20]. Research that has focused on the effects of individualism and collectivism on wellbeing at the individual level (as opposed to through the lens of cross-cultural comparisons) is more consistent in its findings. Across 2 studies on American undergraduates, Bettencourt and Dorr [44] found that wellbeing was negatively associated with individualism, and positively correlated with collectivism, while also showing personal as well as collective self-esteem to be a significant mediator in these relationships. Specific to Australian young people, Scott and colleagues [20] showed an association between those who placed higher levels of importance on individualistic values and a number of social and psychological disadvantages. These included poorer social support, less satisfying social networks and diminished mental health indicators. A later study [45] that explored the individual effects of individualism and collectivism on an Australian sample found that individualism and collectivism were significantly associated with attachment avoidance, but neither related to wellbeing outcomes (operationalised as anxiety). While a study [46] focusing on Turkish University students, found that individualistic social values predicted higher satisfaction with life, while collectivistic values predicted lower satisfaction with life.

A number of studies reviewed divided the concept of individualism into its vertical and horizontal dimensions, as proposed by Triandis and Gelfand [9]. Oishi's [47] crosscultural analysis of data collected from 39 nations is one such study that utilised these dimensions in its analysis. Although not seeking to specifically test the effect of cultural values, but rather goals, Oishi showed that goals around individual autonomy were related to higher levels of satisfaction with life in most cultures. In addition, horizontal individualism (emphasising autonomy and self-reliance) was found to be positively associated with life satisfaction in individualistic nations (but not in the collectivistic nations), while horizontal collectivism was positively associated with life satisfaction in most collectivistic nations. Vertical individualism (emphasising autonomy as well as self-sufficiency and competitiveness with others) was shown to negatively relate to life satisfaction in most individualistic nations, although very marginally and often non-significantly, whereas vertical collectivism yielded mixed results, relating both positively and negatively to life satisfaction in different nations. 
Subsequent research that has distinguished between vertical and horizontal dimensions of individualism and collectivism, and then applied these dimensions to wellbeing at the individual level, have yielded similar findings. In a study of Polish emerging adults Zalewska and Zawdzka [25] found positive relationships between subjective wellbeing and horizontal and vertical collectivism, as well as horizontal individualism, and a negative relationship between subjective wellbeing and vertical individualism. In a study of Australian emerging adults, Humphrey, Bliuc and Molenberghs [23] found that found that vertical individualism was related to greater psychological distress as measured by the DASS-21, whereas horizontal collectivism was related to reduced psychological distress, and vertical collectivism and horizontal individualism were unrelated to distress. A similar study design focusing on US emerging adults [7] similarly found that vertical individualism was negatively related to wellbeing, yet this study also found a negative relationship between horizontal individualism and wellbeing measured through the CES-D. Here horizontal collectivism was positively related to all measures of wellbeing, while vertical collectivism was positively related to some of these measures.

\section{Discussion}

\subsection{Summary of Findings}

Our review focused on research investigating the effects that individualism can have on young people's psychological health within Western environments. Based on an analysis of the existing findings, we can conclude that there is an evolving clarity of understanding on the harmful effects particular traits associated with individualistic social values can have on young people's psychological health. This seems particularly true of traits associated with the vertical dimension of individualism related to extreme self-sufficiency and comparisons with others.

Early cross-cultural research on individualism and wellbeing conducted on general populations showed largely positive correlations, stemming from the freedom and autonomy associated with individualistic environments when compared to collectivistic ones $[15,16,18]$. These positive aspects of individualistic cultures should not be ignored, with individualism providing an array of social freedoms beneficial to living a flourishing life. Our review however reveals two significant caveats in relation to these earlier findings. Firstly, the literature exploring individualism and wellbeing at a personal level (rather than across cultures) suggests that the broad advantages of individualism that exist at the societal level, are less persuasive when applied individually. Findings indicate that whilst individualistic cultures may possess some advantages when compared to collectivistic cultures, this effect either disappears, or outworks as a poor association between individualism and wellbeing, when investigated at the individual level. Conversely, collectivistic orientations tended to relate positively to wellbeing at the individual level. These findings are suggestive of the importance of implementing the collectivistic traits of maintaining strong social relationships within individualistic societies. Secondly, research that has explored the relationship between individualism and wellbeing through its vertical and horizontal sub-dimensions, provides a more nuanced account of how this relationship works. These studies tend to suggest that there are variables inherent in vertical individualism, related to competitiveness and comparing oneself with others that can lead to lower levels of psychological wellbeing in young people, while traits associated with horizontal individualism around self-reliance and autonomy tend to have less of an effect. Such findings are significant in framing our understanding of the relationship between individualism and wellbeing, in that they show us that individualistic traits associated with overt independence and competitiveness may be particularly problematic for one's psychological health. So, whilst individualistic societies allow for many positives, there are also a number of challenges these environments can present to one's wellbeing if they orientate themselves in a highly individualistic way. As highlighted in past research, findings relating aspects of individualism with poorer wellbeing outcomes warrant greater 
consideration as a medium through which young people today experience poorer mental health when compared with previous generations $[5,6]$.

\subsection{Implications of Findings for Further Research}

Firstly, a greater depth of research is needed into the association between individualism and wellbeing, and the way in which various sub-traits (i.e., vertical and horizontal dimensions) of individualism can impact upon it. A more elaborate and detailed description of these relationships would be necessary to understand in greater depth the consequences these cultural influences can have on young people and general populations alike. A greater body of research exploring how these effects operationalise in differing cultural settings is also required. Finally, further research on the way in which Western media and political institutions may influence young people's social value systems and in turn their psychological health through the promotion of individualistic pursuits, are needed.

\subsection{Limitations of the Review}

This review has some limitations. Most notably, despite the availability of a vast quantity of research exploring individualism and collectivism and their effect on behavioural outcomes across cultures, studies that directly addressed the relationship(s) between individualism and psychological wellbeing were scarce. As such, our sample of studies reviewed was relatively small. Furthermore, our review included only peer-reviewed, empirical based journal articles published in English since 1990. This restriction regarding publication type does not meet some criteria (e.g., publication status, publication bias) on the Assessment of Multiple Systematic Reviews (AMSTAR) checklist for assessing the quality of systematic reviews, and may also lead to publication bias. However, because the review's focus was on statistical and empirical evidence that clearly addressed the association between individualism, and wellbeing, gray literature such as reviews should be considered exclusion criteria. Lastly, this review was conducted with a specific focus on Westernized environments, and therefore provides insight into the influence individualistic and collectivistic values have in Western contexts. Such findings are therefore not reflective of the impact individualism and collectivism may have in other cultural contexts, nor may they be entirely consistent within different Western settings.

\section{Conclusions}

Based on the studies reviewed, we propose that whilst individualistic values can have positive associations with one's psychological wellbeing, socially orientating oneself in a highly individualistic way can also manifest in ways that adversely affect psychological health. Indeed, whilst individualistic traits related to personal development and freedom of expression enhance psychological wellbeing, other aspects of individualism such as poor social support, competitiveness and comparisons with others are likely to be linked to a decline in the social connections and mental health of Western young people over the previous few decades.

The research reviewed has pointed towards the prevailing Western cultural dynamism of individualism, as a highly relevant cultural factor when it comes to examining young people's mental health and wellbeing within these settings. With Western environments becoming increasingly individualistic, young people would do well to resist the pull towards the seemingly harmful traits embedded within individualism, and buffer against these by building broad social networks as a means of optimising their psychological health.

Author Contributions: A.H.: Review conception, drafting of manuscript, analysis and interpretation of literature. A.-M.B.: Drafting of manuscript, analysis and interpretation of literature. All authors have read and agreed to the published version of the manuscript.

Funding: This research received no external funding.

Institutional Review Board Statement: Not applicable. 
Informed Consent Statement: Not applicable.

Conflicts of Interest: The authors declare that there is no conflict of interest.

\section{References}

1. Twenge, J.M.; Cooper, A.B.; Joiner, T.E.; Duffy, M.E.; Binau, S. Age, Period, and Cohort Trends in Mood Disorder Indicators and Suicide-Related Outcomes in a Nationally Representative Dataset, 2005-2017. J. Abnorm. Psychol. 2019, 128, 185-199. [CrossRef]

2. Collishaw, S. Annual Research Review: Secular trends in child and adolescent mental health. J. Child Psychol. Psychiatry 2015, 56, 370-392. [CrossRef]

3. Collishaw, S.; Maughan, B.; Natarajan, L.; Pickles, A. Trends in adolescent emotional problems in England: A comparison of two national cohorts twenty years apart. J. Child Psychol. Psychiatry 2010, 51, 885-894. [CrossRef]

4. Twenge, J.M.; Gentile, B.; Dewall, N.; Ma, D.; Lacefield, K.; Schurtz, D. Birth cohort increases in psychopathology among young Americans, 1938-2007: A cross-temporal meta-analysis of the MMPI. Clin. Psychol. Rev. 2010, 30, 145-154. [CrossRef] [PubMed]

5. Twenge, J.M. Generational Differences in Mental Health: Are Children and Adolescence Suffering More, or Less? Am. J. Orthopsychiatry 2011, 81, 469-472. [CrossRef]

6. Eckersley, R. A New Narrative of Young People's Health and Wellbeing. J. Youth Stud. 2011, 14, 627-638. [CrossRef]

7. Nezlek, J.; Humphrey, A. Individualism, Collectivism, and Well-being Among a Sample of Young Americans. Emerg. Adulthood. 2021. [CrossRef]

8. Twenge, J.M.; Campbell, W.K.; Freeman, T. Generational Differences in Young Adults Life Goals, Concern for Others, and Civic Orientation, 1966-2009. J. Personal. Soc. Psychol. 2012, 102, 1045-1062. [CrossRef] [PubMed]

9. Triandis, H.; Gelfland, M. Converging measurement of horizontal and vertical individualism and collectivism. J. Personal. Soc. Psychol. 1998, 74, 118-128. [CrossRef]

10. Oyserman, D.; Coon, H.M.; Kemmelmeier, M. Rethinking individualism and collectivism: Evaluation of theoretical assumptions and meta-analysis. Psychol. Bull. 2002, 128, 3-72. [CrossRef] [PubMed]

11. Bauman, Z. Liquid Modernity; Polity Press: Cambridge, MA, USA, 2000.

12. Hofstede, G.; Hofstede, J.; Minkov, M. Cultures and Organizations: Software of the Mind; Revised and Expanded 3rd Edition; McGraw-Hill USA: New York, NY, USA, 2010.

13. Smith, C.; Christoffersen, K.; Davidson, H.; Snell, P. Lost in Translation: The Dark Side of Emerging Adulthood; Oxford University Press: Oxford, UK, 2011.

14. Humphrey, A.; Forbes-Mewett, H. Social Value Systems and the Mental Health of International Students During the COVID-19 Pandemic. J. Int. Stud. 2021, 11, 58-76. [CrossRef]

15. Diener, E.; Diener, M.; Diener, C. Factors predicting the subjective well-being of nations. J. Personal. Soc. Psychol. 1995, 69, 851-864. [CrossRef]

16. Arrindell, W.A.; Hatzichristou, C.; Wensink, J.; Rosenberg, E.; Van Twillert, B.; Stedema, J.; Meijer, D. Dimensions of national culture as predictors of cross-national differences in subjective well- being. Personal. Individ. Differ. 1997, 23, 37-53. [CrossRef]

17. Schyns, P. Cross-national differences in happiness: Economic and cultural factors explored. Soc. Indic. Res. 1998, 43, 3-26. [CrossRef]

18. Veenhoven, R. Quality of life in individualistic society. Soc. Indic. Res. 1999, 48, 157-186. [CrossRef]

19. Ahuvia, A. Individualism/Collectivism and Cultures of Happiness: A Theoretical Conjecture on the Relationship between Consumption, Culture and Subjective Wellbeing at the National Level. J. Happiness Stud. 2002, 3, 23-36. [CrossRef]

20. Scott, G.; Ciarrochi, J.; Deane, F.P. Disadvantages of being an individualist in an individualistic culture: Idiocentrism, emotional competence, stress, and mental health. Aust. Psychol. 2004, 39, 143-154. [CrossRef]

21. Eckersley, R.; Dear, K. Cultural correlates of youth suicide. Soc. Sci. Med. 2002, 55, 1891-1904. [CrossRef]

22. Eskin, M. The Effects of Individualistic-Collectivistic Value Orientations on Non-Fatal Suicidal Behavior and Attitudes in Turkish Adolescents and Young Adults. Scand. J. Psychol. 2013, 54, 493-501. [CrossRef]

23. Humphrey, A.; Bliuc, A.; Molenberghs, P. The Social Contract Revisited: A re-examination of the influence individualistic and collectivistic value systems have on the psychological wellbeing of young people. J. Youth Stud. 2020, 23, 160-169. [CrossRef]

24. Germani, A.; Delvecchio, E.; Li, J.B.; Lis, A.; Nartova-Bochaver, S.K.; Vazsonyi, A.T.; Mazzeschi, C. The link between individualismcollectivism and life satisfaction among emerging adults from four countries. Appl. Psychol. Health Well-Being 2021, 13, 437-453. [CrossRef]

25. Zalewska, A.M.; Zawadzka, A. Subjective well-being and citizenship dimensions according to individualism and collectivism beliefs among Polish adolescents. Curr. Issues Personal. Psychol. 2016, 4, 155-166. [CrossRef]

26. Steele, L.G.; Lynch, S.M. The Pursuit of Happiness in China: Individualism, Collectivism, and Subjective Well-Being During China's Economic and Social Transformation. Soc. Indic. Res. 2013, 114, 441-451. [CrossRef]

27. Ryff, C. Happiness is everything, or is it? Explorations on the meaning of psychological well-being. J. Personal. Soc. Psychol. 1989, 57, 1069-1081.

28. Moher, D.; Liberati, A.; Tetzlaff, J.; Altman, D.; The PRISMA Group. Preferred Reporting Items for Systematic Reviews and Meta-Analyses: The PRISMA Statement. PLoS Med. 2009, 6, 339.

29. Triandis, H. Individualism and Collectivism; Westview Press: Boulder, CO, USA, 1995. 
30. Triandis, H.C.; Bontempo, R.; Villareal, M.J.; Asai, M.; Lucca, N. Individualism and collectivism: Cross-cultural perspectives on self-ingroup relationships. J. Personal. Soc. Psychol. 1988, 54, 323-338. [CrossRef]

31. Singelis, T.M. The measurement of independent and interdependent self-construals. Personal. Soc. Psychol. Bull. 1994, $20,580-591$. [CrossRef]

32. Hui, H.C. Measurement of individualism-collectivism. J. Res. Personal. 1988, 22, 17-36. [CrossRef]

33. Crocker, J.; Luhtanen, R.K.; Cooper, M.L.; Bouvrette, A. Contingencies of self-worth in college students: Theory and measurement. J. Personal. Soc. Psychol. 2003, 85, 894-908. [CrossRef]

34. Cheng, C.; Cheung, M.; Montasem, A.; International Network of Well-Being Studies. Explaining Differences in Subjective WellBeing Across 33 Nations Using Multilevel Models: Universal Personality, Cultural Relativity, and National Income. J. Personal. 2016, 84, 46-58.

35. Suh, E.; Diener, E.; Oishi, S.; Triandis, H.C. The shifting basis of life satisfaction judgments across cultures: Emotions versus norms. J. Personal. Soc. Psychol. 1998, 74, 482-493. [CrossRef]

36. Inglehart, R.; Basanez, M.; Moreno, A. Human Values and Beliefs: A Cross-Cultural Sourcebook; University of Michigan Press: Ann Arbor, MI, USA, 1998.

37. Diener, E.; Emmons, R.A.; Larsen, R.J.; Griffin, S. The satisfaction with life scale. J. Pers. Assess. 1985, 49, 71-75. [CrossRef] [PubMed]

38. Osman, A.; Wong, J.L.; Bagge, C.L.; Freedenthal, S.; Gutierrez, P.M.; Lozano, G. The Depression Anxiety Stress Scales-21 (DASS-21): Further examination of dimensions, scale reliability, and correlates. J. Clin. Psychol. 2012, 68, 1322-1338. [CrossRef]

39. Radloff, L.S. The CES-D Scale: A self-report depression scale for research in the general population. Appl. Psychol. Meas. 1977, 1 , 385-401. [CrossRef]

40. Beck, A.T.; Steer, R.A.; Brown, G.K. Manual for Beck Depression Inventory-II; Psychological Corporation: San Antonio, TX, USA, 1996.

41. Eskin, M. The effects of religious versus secular education on suicide ideation and suicidal attitudes in adolescents in Turkey. Soc. Psychiatry Psychiatr. Epidemiol. 2004, 39, 536-542. [CrossRef] [PubMed]

42. Ogihara, Y.; Uchida, Y. Does individualism bring happiness? Negative effects of individualism on interpersonal relationships and happiness. Front. Psychol. 2014, 5, 135.

43. Krys, K.; Zelenski, J.M.; Capaldi, C.A.; Park, J.; Tilburg, W.; Osch, Y.; Haas, B.W.; Bond, M.H.; Dominguez-Espinoza, A.; Xing, C.; et al. Putting the "we" into well-being: Using collectivism-themed measures of well-being attenuates well-being's association with individualism. Asian J. Soc. Psychol. 2019, 22, 256-267. [CrossRef]

44. Bettencourt, B.A.; Dorr, N. Collective self-esteem as a mediator of the relationship between allocentrism and subjective well-being. Personal. Soc. Psychol. Bull. 1997, 23, 955-964. [CrossRef]

45. Lin, H.; Chew, P.Y.G.; Wilkinson, R.B. Young adults' attachment orientations and psychological health across cultures: The moderating role of individualism and collectivism. J. Relatsh. Res. 2017, 8, 1-14. [CrossRef]

46. Yetim, U. The Impacts of Individualism/Collectivism, Self-Esteem, and Feeling of Mastery on Life Satisfaction among the Turkish University Students and Academicians. Soc. Indic. Res. 2003, 61, 297-317. [CrossRef]

47. Oishi, S. Goals as cornerstones of subjective well-being: Linking individuals with cultures. In Subjective Well-Being Across Cultures; Diener, E.F., Suh, E.M., Eds.; MIT Press: Cambridge, MA, USA, 2000; pp. 87-112. 